\title{
Aerobic and Anaerobic Energy Expenditure During Rest and Activity in Montane Bufo b. boreas and Rana pipiens
}

\author{
Cynthia Carey ${ }^{1}$ \\ Division of Biological Sciences, University of Michigan, Ann Arbor, Michigan 48109 USA
}

\begin{abstract}
Summary. The relations of standard and active aerobic and anaerobic metabolism and heart rate to body temperature $\left(T_{\mathrm{b}}\right)$ were measured in montane groups of Bufo b. boreas and Rana pipiens maintained under field conditions. These amphibians experience daily variation of $T_{\mathrm{b}}$ over $30^{\circ} \mathrm{C}$ and $23^{\circ} \mathrm{C}$, respectively (Carey, 1978). Standard and active aerobic and anaerobic metabolism, heart rate, aerobic and anaerobic scope are markedly temperature-dependent with no broad plateaus of thermal independence. Heart rate increments provide little augmentation of oxygen transport during activity; increased extraction of oxygen from the blood probably contributes importantly to oxygen supply during activity. Development of extensive aerobic capacities in $B u f o$ may be related to aggressive behavior of males during breeding. Standard metabolic rates of both species are more thermally dependent than comparable values for lowland relatives. Thermal sensitivity of physiological functions may have distinct advantages over thermally compensated rates in the short growing season and daily thermal fluctuations of the montane environment.
\end{abstract}

\section{Introduction}

Many ectothermic animals encounter some, if not substantial, daily and seasonal variation in body temperature $\left(T_{\mathrm{b}}\right)$ due to behavioral choice (Brett, 1971) or fluctuations in the thermal environment. Since extensive research over the past few decades has established that most physiological rates are partially or totally temperature-dependent (Precht, 1973), basic questions remain unanswered concerning the regulation of physiological processes during change in $T_{\mathrm{b}}$ and the role of fluctuating $T_{\mathrm{b}}$ in the energetics of ectothermic species. On the assumption that fluctuations in $T_{\mathrm{b}}$ could pose substantial problems for the maintenance

1 Present address: Department of EPO Biology, University of Colorado, Boulder, Colorado 80309 USA 
of homeostasis (Hochachka and Somero, 1973), much attention has been directed towards understanding what mechanisms ectothermic animals might possess for thermal compensation of physiological and biochemical rates (see reviews by Bullock, 1955; Prosser, 1958; Fry, 1958; Fry and Hochachaka, 1970; Hazel and Prosser, 1974). The temperature insensitive rates of oxygen consumption in certain intertidal invertebrates (Newell, 1966; Newell and Northcroft, 1967; Newell and Pye, 1970, 1971) have often been cited to suggest that ectotherms encountering broad and rapid variations in $T_{\mathrm{b}}$ may have the most developed capacities for thermal compensation. However, thermal compensation appears to be only one mechanism for dealing with variation in $T_{\mathrm{b}}$, since other intertidal invertebrates and terrestrial ectotherms lack such broad plateaus of temperature insensivity in physiological rates (Tribe and Bowler, 1968; Mangum and Sassaman, 1969; Coyer and Mangum, 1973; Bennett and Dawson, 1976). Despite the potential benefits of constant $T_{\mathrm{b}}$ and temperature compensation, the possibilities still exist that fluctuating $T_{\mathrm{b}}$ and temperature dependent rates may be advantageous in certain habitats.

The purpose of this study was to determine the relation between $T_{\mathrm{b}}$ and resting and active aerobic and anaerobic metabolism, heart rate, and the contribution of heart rate in support of activity in two terrestrial ectotherms. These physiological rates were chosen since they are important processes which vary with $T_{\mathrm{b}}$ and degree of activity (Moberly, 1968; Bennett, 1972; Brett and Glass, 1973; Seymour, 1973; Gatten, 1974a). Montane populations of Bufo b. boreas and Rana pipiens were chosen for the study because $T_{\mathrm{b}}$ of these Bufo can fluctuate over a $30^{\circ} \mathrm{C}$ span in a $24-\mathrm{h}$ period (Carey, 1978) and $T_{\mathrm{b}}$ of Rana vary up to $23^{\circ} \mathrm{C}$ daily (Carey, unpubl. data). These variations in $T_{\mathrm{b}}$ are among the widest and most rapid recorded for ectothermic species. The intent of the study was to determine the physiological responses of these groups to natural variation of $T_{\mathrm{b}}$ in the field. Therefore, they were maintained under natural conditions of temperature and photoperiod. The physiological responses of Bufo to acclimation to constant and fluctuating $T_{\mathrm{b}}$ in the laboratory will be presented in a subsequent paper (Carey, 1979a).

\section{Materials and Methods}

\section{Capture and Maintenance of Animals}

Fifty adult $B$ fo $b$. boreas (mean mass $=40.2, \mathrm{SE}=5.6$, range $=27.1-58.4 \mathrm{~g}$ ) were captured at altitudes between 3,000 and 3,355 $\mathrm{m}$ in the East River valley near the Rocky Mountain Biological Laboratory (RMBL), Gothic, Gunnison County, Colorado. Thirty-seven Rana pipiens (mean mass $=34.8, \mathrm{SE}=$ 3.2 , range $=22.3-47.3 \mathrm{~g})$ were collected at Allen's Pond $(2,654 \mathrm{~m})$ near Curecanti Creek, Gunnison County, Colorado. Toads and frogs were maintained at RMBL in $1 \times 0.3 \times 0.15 \mathrm{~m}$ plastic containers with screen tops. Tenebrio larvae and grasshoppers were provided several times weekly. The cages were placed on the ground near a building, where the animals had access to shade at all times and to sunlight on clear days. Body temperatures of captive toads, measured orally with a thermistor used in conjunction with a YSI telethermometer, fell within the same daily ranges documented for toads in the field (Carey, 1978).

The effects of body temperature on standard and active rates of aerobic and anaerobic metabolism and heart beat were tested at RMBL at an altitude of 2,900 $\mathrm{m}$ in June and July, 1973 and 
1974. Each animal was used only once and was in captivity no more than a week before testing. Forty-two of the Bufo were males. The number of females was insufficient to determine whether any variance in the data is attributable to sex. The sexes of the Rana were undetermined.

\section{Standard Metabolism and Heart Rate}

Oxygen consumption was measured in a closed-circuit system similar to that described by Gatten (1974a). Preliminary experiments indicated that rates of oxygen consumption declined continuously for 8 to $10 \mathrm{~h}$ after an animal was placed in the chamber and that following a 10-h equilibration period, values of oxygen consumption were lower between 0300 and 0600 than at any other time of day or night. Therefore, the toads and frogs were placed in the metabolism chamber between 1700 and $1800 \mathrm{~h}$ so that the values of oxygen consumption recorded during 0300 and $0600 \mathrm{~h}$ the next morning represented true standard metabolic rates (SMR).

Toads and frogs were fasted 3 days before use. Each animal was weighed to the nearest $0.2 \mathrm{~g}$ on an Ohaus balance, accurate to $0.01 \mathrm{~g}$. It was then placed in a metabolism chamber consisting of a Plexiglas cylinder $15 \mathrm{~cm}$ long, $16 \mathrm{~cm}$ in diameter, and $45 \mathrm{~cm}$ in circumference. A saturated sponge provided water in the chamber for the animal. Mass loss was limited to 2-4 percent of the initial value during the $16-18 \mathrm{~h}$ test period. The chamber was placed in a cabinet in which air temperature could be controlled within $0.5^{\circ} \mathrm{C}$ between 5 and $35^{\circ} \mathrm{C}$.

A peristaltic pump circulated air via tygon tubing through the closed system at a rate of approximately $120-160 \mathrm{~cm}^{3} / \mathrm{min}$. The air leaving the metabolism chamber was channelled sequentially through a drying column filled with Drierite (anhydrous $\mathrm{CaSO}_{4}$ ), a flowmeter, a Beckman F 3 paramagnetic oxygen analyzer, and then back to the chamber. Room air was sampled from air supplied by a Little Giant pump (Gelman Industries) 5 min every hour. The oxygen content of the air in the system never dropped below $20 \%$ during the tests. The fractional oxygen concentration of the air was recorded by a Honeywell potentiometric recorder every $15 \mathrm{~s}$ between 2200 and $0900 \mathrm{~h}$. The oxygen consumption of the animal was calculated for each hour period between 0300 and $0600 \mathrm{~h}$ and the two lowest hourly values were averaged as the estimate of SMR. The results were discarded if any activity, evidenced by an abrupt decline in oxygen concentration of the system, occurred between 0300 and $0600 \mathrm{~h}$.

Heart rate was measured at various body temperatures during tests of SMR in Bufo b. boreas. Three small gold-plated safety pins were inserted through the skin and musculature of both forelimbs and a hindlimb of each toad before it was placed in the metabolism chamber. These pins were connected by alligator clamps to flexible leads that left the metabolism chamber through an air-tight port. Electrocardiograms, from which heart rates were determined, were recorded automatically for 1 min intervals each hour between 2200 and $0900 \mathrm{~h}$ by a Model 126 Sanborn recorder used in conjunction with a Grass P5C preamplifier. The rates coinciding with the periods of minimal oxygen consumption were designated the standard heart rates (SHR).

The animal was removed from the chamber at $0900 \mathrm{~h}$ and its oral body temperature was taken immediately with a small animal thermistor used in conjuction with a YSI telethermometer.

\section{Metabolism and Heart Rate During Activity}

The animal was returned to the metabolism chamber following measurement of standard metabolism and body temperature. The EKG leads were disconnected from the safety-pin electrodes. Air was circulated very slowly for approximately an hour while the animal came to thermal equilibrium with its surroundings. The air flow was then increased for $5 \mathrm{~min}$ to flush the chamber thoroughly. A sample of the excurrent air was collected in a balloon which was attached immediately to a drying train filled with Drierite. The air passed from the balloon through the drying train into the Beckman F3 oxygen analyzer at a rate of $120-160 \mathrm{~cm}^{3} / \mathrm{min}$. Meanwhile, the incurrent and excurrent air lines were disconnected, and the ports were sealed. The air-tight metabolism chamber was then rotated by a small motor at approximately 5-7 rev/min. The speed of rotation was increased until the animal could remain upright only by using exceedingly rapid and vigorous running and hopping movements. Once the speed of rotation was adjusted, the door of the controlled temperature cabinet was closed. Two horizontal bars on the inside of the chamber prevented 
the animal from sliding as the chamber rotated. Some animals fell onto their backs and struggled to right themselves. Rana pipiens fatigued rapidly and handling of the frogs after the $5 \mathrm{~min}$ exercise period failed to induce struggling. Bufo continued moving in the chamber for more than $1 \mathrm{~h}$ without visible signs of fatigue. They showed vigorous escape responses after removal from the chamber. No significant differences existed between the rates of oxygen consumption (per unit time) of individual toads when tested over 10,20 , or $30 \mathrm{~min}$. Therefore, oxygen consumption of active toads was routinely measured after $10 \mathrm{~min}$ of exercise.

At the termination of the activity period, the rotation of the chamber was stopped, the excurrent air port was unclamped, and a second balloon was attached. An air line was connected via a tube to the third balloon located in the chamber. As the balloon in the chamber inflated, the volume of the chamber rapidly decreased. This forced the air out the excurrent air port into the second balloon. It was assumed that the air in the chamber was well mixed because the animal was constantly moving around during rotation. The balloon attached to the excurrent air port was then disconnected and the air it contained directed through the drying train into the oxygen analyzer. Meanwhile, the animal quickly was removed from the chamber. A thermistor was inserted into the esophagus to measure body temperature. The animal was then weighed to the nearest $0.1 \mathrm{~g}$. The active metabolic rate was calculated from the decrement of oxygen concentration in the chamber over the 5- or 10 -min period of activity. All gas concentrations were corrected to STPD.

Electrocardiograms of Bufo b. boreas subjected to $10 \mathrm{~min}$ of intense activity were recorded for $30 \mathrm{~s}$ during measurement of body temperature, just after removal of the toads from the metabolism chamber. The rapid attachment of leads to the safety pin electrodes and the short span of the measurement prevented the body temperature from changing appreciably from the level existing within the chamber. It was assumed that immediate post-activity heart rates closely approximated the heart rate during activity.

\section{Standard and Active Anaerobic Metabolism}

The contribution of anaerobic energy expenditure to activity at body temperatures from 10 to $30^{\circ} \mathrm{C}$ was estimated in 31 Bufo b. boreas and 29 Rana pipiens. Each animal was weighed to the nearest $0.1 \mathrm{~g}$ on an Ohaus balance and allowed to rest overnight at the desired test temperature in the metabolism chamber. Sixteen toads and 15 frogs measured after $16 \mathrm{~h}$ in the resting state were removed from the chamber quickly at about $0900 \mathrm{~h}$. The animals were sacrificed by concussion and immediately homogenized by a Waring blender in a volume of chilled $0.6 \mathrm{~N}$ perchloric acid equalling 4 times their body mass. Fifteen toads and 14 frogs were subjected to 10 min or $5 \mathrm{~min}$ activity, respectively, in the rotating chamber after resting overnight at the appropriate temperature. After removal from the chamber, the body temperature of these animals was recorded rapidly prior to sacrifice and homogenization in cold perchloric acid. The maximum interval between removal and homogenization was approximately $20 \mathrm{~s}$.

A portion of the total body homogenate was centrifuged for $30 \mathrm{~min}$ in a clinical centrifuge and frozen for later analysis. The supernatant was treated with reagents from a Boehringer-Mannheim lactate test kit and the lactate concentration assayed at $366 \mathrm{~nm}$ on a Cary 17 spectrophotometer.

\section{Statistics}

In cases where a function was clearly linear when plotted against body temperature on an arithmetic grid (lactate concentration) or on a semi-logarithmic grid (oxygen consumption and heart rate), the regression equations best describing the relation of the function to body temperature were computed by the method of least squares. Computation of the equations for oxygen consumption and heart rate used logarithmically transformed data. In cases where a function was obviously non-linear, least square polynomial regressions of increasing order were computed until no significant improvement in fit was obtained. A one-way analysis of covariance was used to test for equality of slopes and intercepts of linear regressions. Polynomial regressions were not compared statistically owing to an absence of suitable tests. 
Fig. 1. The relation of oxygen consumption $\left(\dot{V}_{\mathrm{O}_{2}}\right)$ of Bufo b. boreas to body temperature $(T)$ under standard conditions (circles) and over 10 min of vigorous activity (squares). Regression lines are constructed on the basis of Eq. 1 and 2. Data are plotted on a semilogarithmic grid. Resting values represent the mean of the two lowest hourly records. Active rates represent single measurements. $N=50$. Arrows signify the intercept of the regression line with the ordinate

\section{Results}

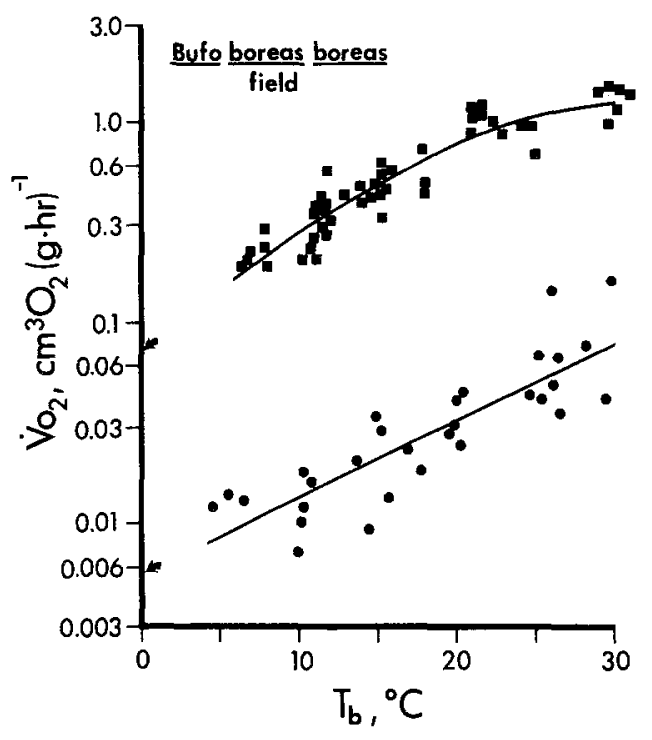

Standard and Active Aerobic Metabolism

Oxygen consumption $\left(\dot{V}_{\mathrm{O}_{2}}\right)$ of resting Bufo b. boreas that had been maintained under field conditions increases directly with body temperature $\left(T_{\mathrm{b}}\right)$, with little evidence of pronounced plateaus of thermal independence (Fig. 1). The equation best describing the relation of $\dot{V}_{\mathrm{O}_{2}}$ (as standard metabolic rate) to $T_{\mathrm{b}}$ is:

$$
\begin{aligned}
& \log \mathrm{SMR}=-2.23+0.037 T_{\mathrm{b}} \\
& \left(n=30, r=0.84, S_{\mathrm{yx}}=0.183, S_{\mathrm{b}}=0.004\right),
\end{aligned}
$$

where oxygen consumption is expressed as $\mathrm{cm}^{3} \mathrm{O}_{2}(\mathrm{~g} \cdot \mathrm{h})^{-1}$ and $T_{\mathrm{b}}$ is in degrees Celsius (C). The $Q_{10}$ for this relationship is 2.37 between 0 and $30^{\circ} \mathrm{C}$. The polynomial equation best describing the relation of active metabolic rate to $T_{\mathrm{b}}$ is:

$$
\begin{aligned}
& \log \mathrm{AMR}=-1.13+0.067 T_{\mathrm{b}}-0.0008\left(T_{\mathrm{b}}\right)^{2} \\
& \left(n=49, r=0.92, S_{\mathrm{yx}}=0.094\right) .
\end{aligned}
$$

No fatigue was observed after $10 \mathrm{~min}$ of activity. The $Q_{10}$ for this relation decreases continuously from 3.72 in the interval $5-10^{\circ} \mathrm{C}$ to 1.42 between 25 and $30^{\circ} \mathrm{C}$.

Oxygen consumption of resting Rana pipiens maintained under field conditions increases with $T_{\mathrm{b}}$ (Fig. 2) according to the relation:

$$
\begin{aligned}
& \log \mathrm{SMR}=-2.34+0.049 T_{\mathrm{b}} \\
& \left(n=22, r=0.94, S_{\mathrm{yx}}=0.140, S_{\mathrm{b}}=0.004\right) .
\end{aligned}
$$

The overall $Q_{10}$ for this relationship between 0 and $30^{\circ} \mathrm{C}$ is 3.06 . Ranges of pronounced thermal independence are not evident in resting rates (Fig. 2). 


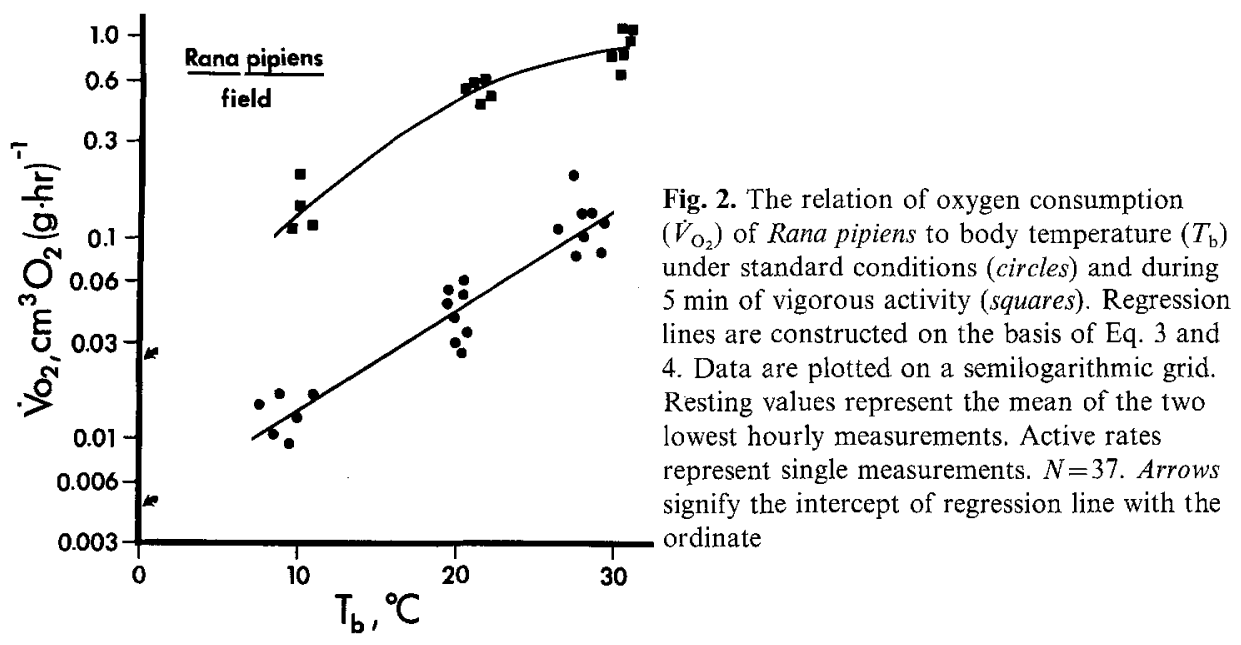

The polynomial regression best describing the relation of oxygen consumption to $T_{\mathrm{b}}$ for active Rana is:

$$
\begin{aligned}
& \log \mathrm{AMR}=-1.65+0.93 T_{\mathrm{b}}-0.0013\left(T_{\mathrm{b}}\right)^{2} \\
& \left(n=15, r=0.96, S_{\mathrm{yx}}=0.96\right) .
\end{aligned}
$$

Frogs were visibly exhausted after $5 \mathrm{~min}$ of activity and did not respond to mechanical stimulation. The $Q_{10}$ for this relationship decreases continuously from 4.85 for the interval 5 to $10^{\circ} \mathrm{C}$ to 1.37 between 25 and $30^{\circ} \mathrm{C}$. Analysis of covariance of the equations relating oxygen consumption $T_{\mathrm{b}}$ for resting Bufo and Rana (Eq. 1 and 3) indicates that the slopes are statistically indistinguishable $(P=0.07)$, but that the intercepts differ significantly $(P<0.01)$.

The aerobic scope for activity, i.e., the difference between active and standard rates of oxygen consumption at a given temperature, are listed in Table 1 for Bufo and Rana. These values are calculated from Eq. 1-4. The aerobic scope of Bufo is higher than that of Rana at all temperatures. Another parameter allowing the comparison of active and standard metabolic rates is the ratio of AMR to SMR, an indication of relative metabolic expansibility during activ-

Table 1. Aerobic and anaerobic scope of Bufo boreas boreas and Rana pipiens maintained under

\begin{tabular}{|c|c|c|c|c|}
\hline \multirow{2}{*}{$\begin{array}{l}T_{\mathrm{b}} \\
{ }^{\circ} \mathrm{C}\end{array}$} & \multicolumn{2}{|l|}{ Bufo } & \multicolumn{2}{|l|}{ Rana } \\
\hline & $\begin{array}{l}\text { Aerobic } \\
\mathrm{cm}^{3} \mathrm{O}_{2}(\mathrm{~g} \cdot \mathrm{h})^{-1}\end{array}$ & $\begin{array}{l}\text { Anaerobic } \\
\mathrm{mg} \mathrm{lactate} \\
(\mathrm{g} \cdot 10 \mathrm{~min})^{-1}\end{array}$ & $\begin{array}{l}\text { Aerobic } \\
\mathrm{cm}^{3} \mathrm{O}_{2}(\mathrm{~g} \cdot \mathrm{h})\end{array}$ & $\begin{array}{l}\text { Anaerobic } \\
\text { mg lactate } \\
(\mathrm{g} \cdot 5 \mathrm{~min})^{-1}\end{array}$ \\
\hline 10 & 0.27 & 0.50 & 0.12 & 0.79 \\
\hline 20 & 0.74 & 0.59 & 0.41 & 1.17 \\
\hline 30 & 1.12 & 0.70 & 0.69 & 1.33 \\
\hline
\end{tabular}
field conditions. Values are calculated from equations $1-4$ (aerobic) and $5-8$ (anaerobic) 
Fig. 3. The relation of lactate concentration to body temperature $\left(T_{\mathrm{b}}\right)$ in Bufo b. boreas and Rana pipiens. Values for resting and active animals are represented by circles and squares, respectively. Bufo and Rana were subjected to vigorous activity for 10 and $5 \mathrm{~min}$, respectively. Regression lines were constructed on the basis of Eq. 5-8. Each point represents a single measurement. $N=31$ for Bufo and 29 for Rana

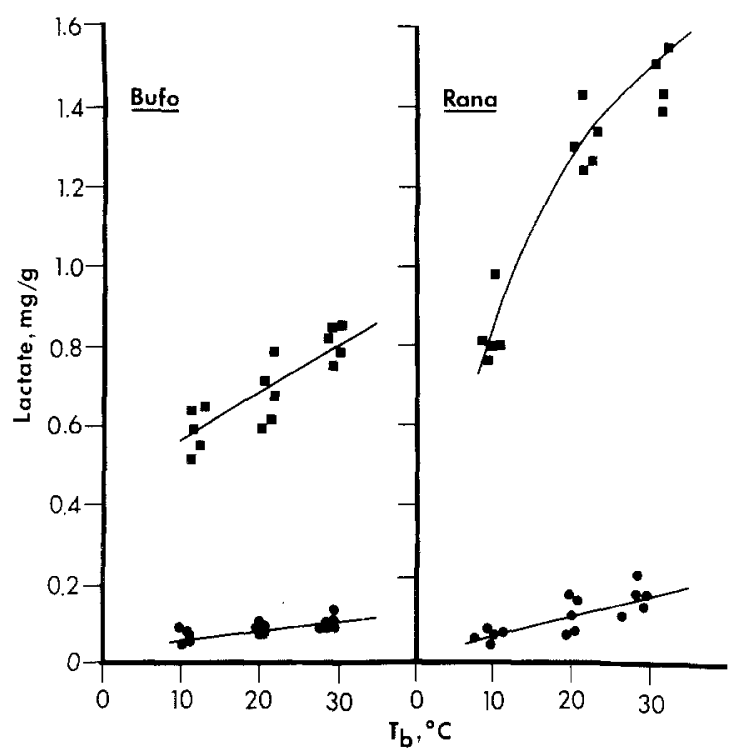

ity. Calculations of ratios over $5^{\circ} \mathrm{C}$ intervals from 5 to $30^{\circ} \mathrm{C}$ from Eq. $1-4$ reveal that the ratio extends from $16.2\left(5^{\circ} \mathrm{C}\right)$ to $24.3\left(20^{\circ} \mathrm{C}\right)$ in Bufo. The corresponding range for Rana is $6.3\left(30^{\circ} \mathrm{C}\right)$ to $10.8\left(25^{\circ} \mathrm{C}\right)$.

\section{Standard and Active Anaerobic Metabolism}

Total body concentrations of lactate for resting and active Bufo b. boreas and Rana pipiens are presented in Fig. 3. Lactate concentrations of both resting and active Bufo and Rana rise with increasing $T_{\mathrm{b}}$ according to the relations best described by the regression equations listed in Table 2. Statistical comparison of the equations for active toads and frogs are not feasible, but it is clear that lactate concentrations increase much more dramatically with $T_{\mathrm{b}}$ in frogs than in toads. Analysis of covariance of the equations for lactate concentrations

Table 2. Regression equations for body lactate concentrations of resting and active Bufo b. boreas and Rana pipiens maintained under field conditions. Lactate concentrations are in $\mathrm{mg} / \mathrm{g}$ body mass and body temperature $\left(T_{\mathrm{b}}\right)$ in degrees Celsius

\begin{tabular}{lll}
\hline Resting Bufo & Lactate $=0.039+0.0022 T_{\mathrm{b}}$ \\
& $n=16, r=0.82, S_{\mathrm{yx}}=0.012, S_{\mathrm{b}}=0.004$ \\
Active Bufo & Lactate $=0.44+0.012 T_{\mathrm{b}}$ \\
& $n=15, r=0.82, S_{\mathrm{yx}}=0.063, S_{\mathrm{b}}=0.002$ \\
Resting Rana & Lactate $=0.022+0.0051 T_{\mathrm{b}}$ \\
& $n=15, r=0.81, S_{\mathrm{yx}}=0.03 \mathrm{I}, S_{\mathrm{b}}=0.001$ \\
Active Rana & $\begin{array}{l}\text { Lactate }=0.21+0.076 T_{\mathrm{b}}-0.0011\left(T_{\mathrm{b}}\right)^{2} \\
\end{array}$ \\
& $n=14, r=0.95, S_{\mathrm{yx}}=0.092$
\end{tabular}


in resting frogs and toads (Eq. 5 and 7) indicates that both the slopes and intercepts differ significantly $(P<0.01)$. Again, the effect of temperature is more marked in Rana than in Bufo.

The amounts of lactate produced per g body mass during 5 and $10 \mathrm{~min}$ of vigorous activity in Rana and Bufo, respectively, are presented in Table 1. These values, defined here as the difference between resting and active amounts, or anaerobic scope, were estimated on the basis of Eq. 5-8. At all temperatures the anaerobic scope of Rana during only $5 \mathrm{~min}$ of activity is higher than that of Bufo after $10 \mathrm{~min}$ of activity.

\section{Standard and Active Heart Rates}

Heart rates of resting and active $B u f o b$. boreas maintained under field conditions are strongly dependent on temperature with no pronounced plateaus of temperature independence (Fig. 4). The equation best describing the relation of standard heart rate (SHR) in beats/min to body temperature $\left(T_{\mathrm{b}}\right)$ in degrees Celsius (C) is:

$$
\begin{aligned}
& \log \mathrm{SHR}=0.96+0.032 T_{\mathrm{b}} \\
& \left(n=23, r=0.95, S_{\mathrm{yx}}=0.077, S_{\mathrm{b}}=0.002\right) .
\end{aligned}
$$

The $Q_{10}$ for this relation between 0 and $30^{\circ} \mathrm{C}$ is 2.09 . The equation best describing the relation of active heart rate (AHR) to body temperature $\left(T_{\mathrm{b}}\right)$ is

$$
\begin{aligned}
& \log \text { AHR }=1.198+0.037 T_{\mathrm{b}}-0.0003\left(T_{\mathrm{b}}\right)^{2} \\
& \left(n=50, r=0.95, S_{\mathrm{yx}}=0.059\right) .
\end{aligned}
$$

The $Q_{10}$ for this relationship decreases continuously from 2.18 between 5 and $10^{\circ} \mathrm{C}$ to 1.57 between 25 and $30^{\circ} \mathrm{C}$. The heart rate increment, i.e., the difference between active and standard rates, is 15 beats $/ \mathrm{min}$ at $10^{\circ} \mathrm{C}, 25$ beats $/ \mathrm{min}$ at $20^{\circ} \mathrm{C}$, and 21 beats $/ \mathrm{min}$ at $30^{\circ} \mathrm{C}$. These values are estimated from Eq. 9 and 10. Heart rates during activity increased approximately $1.8,1.6$, and 1.2 times resting values at 10,20 , and $30^{\circ} \mathrm{C}$, respectively.

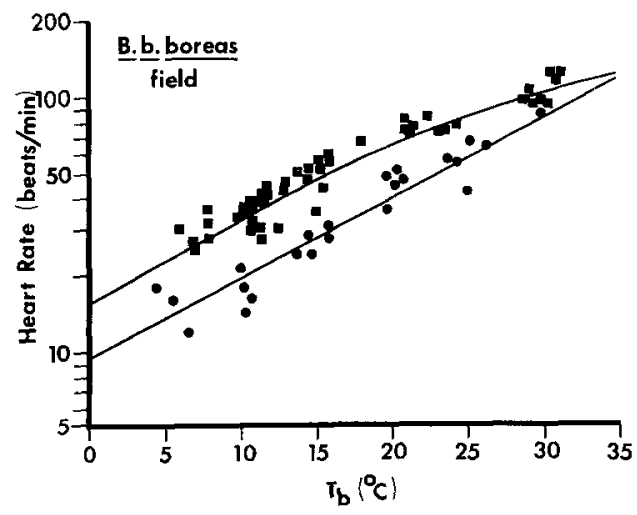

Fig. 4. The relations of standard (circles) and active (squares) heart rates of Bufo b. boreas to body temperature $\left(T_{\mathrm{b}}\right)$. Regression lines are constructed on the basis of Eq. 9 and 10 . Animals were subjected to vigorous activity for $10 \mathrm{~min}$. Data are plotted on a semi-logarithmic grid. $N=50$ 


\section{Discussion}

\section{Standard Metabolism}

The SMR of montane Bufo and Rana are directly dependent on temperature and exhibit no pronounced plateaus of thermal independence over the range of $T_{\mathrm{b}}$ they experience daily in the field (Figs. 1 and 2). The $Q_{10}$ values for SMR of montane toads and frogs generally exceed those reported for similar lowland forms (Table 3). Additionally, Thamnophis elegans vagrans living near the upper altitudinal limit of their distribution $(2,900 \mathrm{~m})$ exhibit a highly temperature-dependent SMR and a higher $Q_{10}$ than those of lowland Thamnophis (Carey, unpubl. data). The higher $Q_{10}$ in montane ectotherms may represent methodological differences among studies, since the animals in other studies may not have been fully resting. Levels of activity above resting often involve different relations of metabolism to temperature than those characterizing standard conditions (Brett and Glass, 1973; Newell and Bayne, 1973; Bayne et al., 1973; Dmi'el and Rappeport, 1976). Similarly, the data collected for this report were obtained in the dark between 0300 and $0600 \mathrm{~h}$ when SMR was minimal compared to other parts of the daily cycle. Other studies measured SMR during the day or at unreported times. The presence of light during measurement or the time during the diel cycle in which measurements are made may also affect the thermal sensitivity of SMR (Turney and Hutchison, 1974). The differences may also result from the observation that toads maintained under fluctuating thermal conditions exhibit a more thermally sensitive SMR than those acclimated to constant temperatures (Carey, 1979a). However, the differences

Table 3. $Q_{10}$ values for resting oxygen consumption of Bufo and Rana. Values of other studies may not necessarily have been calculated from standard measurements

\begin{tabular}{llrl}
\hline Species & $Q_{10}$ & Temperature span & Reference \\
\hline B. b. boreas & 2.37 & $0-30^{\circ} \mathrm{C}$ & This study \\
B. boreas (lowland) & 0.98 & $5-15^{\circ} \mathrm{C}$ & Hutchison et al., 1968 \\
& 1.87 & $15-25^{\circ} \mathrm{C}$ & \\
B. b. boreas (lowland) & 1.11 & $14-24^{\circ} \mathrm{C}$ & Tashian and Ray, 1957 \\
B. boreas halophilus & 1.19 & $14-24^{\circ} \mathrm{C}$ & Tashian and Ray, 1957 \\
B. cognatus & 2.70 & $5-15^{\circ} \mathrm{C}$ & Hutchison et al., 1968 \\
& 1.56 & $15-25^{\circ} \mathrm{C}$ & \\
B. cognatus & 1.3 & $10-30^{\circ} \mathrm{C}$ & Seymour, 1973 \\
B. marinus & 1.91 & $15-25^{\circ} \mathrm{C}$ & Hutchison et al., 1968 \\
B. americanus & 4.5 & $5-15^{\circ} \mathrm{C}$ & Hutchison et al., 1968 \\
B. terrestris & 1.1 & $15-25^{\circ} \mathrm{C}$ & \\
R. pipiens & 2.63 & $5-15^{\circ} \mathrm{C}$ & Hutchison et al., 1968 \\
R. pipiens & 1.41 & $15-25^{\circ} \mathrm{C}$ & \\
R. pipiens & 3.06 & $0-30^{\circ} \mathrm{C}$ & This study \\
R. clamitans & 2.7 & $15-15^{\circ} \mathrm{C}$ & Hutchison et al., 1968 \\
$R$ sylvatica & 2.41 & $10-35^{\circ} \mathrm{C}$ & \\
\hline
\end{tabular}


in $Q_{10}$ between montane and lowland groups could indeed be real, since SMR of montane Bufo b. boreas are more thermally sensitive than those of lowland Bufo boreas halophilus maintained and measured under identical conditions (Carey, 1979a).

The potential benefit of thermally sensitive rates may relate to the special problems of terrestrial ectotherms in the montane environment. The season for growth, reproduction, and storage of glycogen and lipid for winter use is short (3-4 months) at high elevations. Ambient temperatures $\left(T_{\mathrm{a}}\right)$ during the summer fluctuate up to $20^{\circ} \mathrm{C}$ daily and nighttime $T_{\mathrm{a}}$ fall close to or below freezing. On cloudy days, $T_{\mathrm{a}}$ may not reach $15^{\circ} \mathrm{C}$ (Carey, 1978). Toads are active at cold $T_{\mathrm{b}}$ at night and on cloudy days, but few prey are active in the cold. Although digestive efficiency is greater at cold $T_{\mathrm{b}}$, more calories per day can be extracted from the food at warm $T_{\mathrm{b}}$, provided that the gut is continuously full of food (Carey, unpubl. data). Therefore, the amount of time each summer in which the toads can attain warm $T_{\mathrm{b}}$ and materials from the food for maintenance, growth, and reproduction is quite limited. Any mechanism serving to minimize maintenance costs in the cold and to maximize synthetic processes at warm $T_{\mathrm{b}}$ at which enzyme activities might be more optimal could well be advantageous. A thermally sensitive SMR would lower maintenance costs at cold $T_{\mathrm{b}}$ and perhaps make more energy available to devote to synthetic processes at warm $T_{\mathrm{b}}$. Elaborating this theory to an extreme interpretation, these amphibians could be using thermally sensitive rates and the thermal variety of their montane habitat to partition the participation of various metabolic pathways to various ranges of $T_{\mathrm{b}}$.

A similar thermally sensitive SMR with a $Q_{10}$ approaching 400 at $T_{\mathrm{b}}$ below $10^{\circ} \mathrm{C}$ has been observed in high latitude snakes (Aleksiuk, 1976). The major benefit of such high $Q_{10}$ would be to reduce energy expenditure to an absolute minimum at cold $T_{\mathrm{b}}$ when the snakes are totally inactive (Aleksiuk, 1976). Therefore, thermally sensitive physiological rates appear to be advantageous in certain habitats when time at warm $T_{\mathrm{b}}$ is limited by short growing seasons and daily variation in $T_{\mathrm{a}}$.

\section{Aerobic Metabolism during Activity}

Rates of oxygen consumption of active toads and frogs are also temperature dependent, although rates become less sensitive to temperature at higher $T_{\mathrm{b}}$ (Figs. 1 and 2). The reduced thermal sensitivity of AMR at high $T_{\mathrm{b}}$ may reflect limited abilities of the oxygen uptake and transport processes for sustaining maximal aerobic expenditures (Bennett, 1972).

Maximal rates of oxygen consumption of Bufo clearly exceed those of Rana at all $T_{\mathrm{b}}$ (Figs. 1 and 2, Seymour, 1973). A more convenient comparison of the aerobic capacities for exercise is the calculation of metabolic scope. This measure, formulated by Fry (1947), can be used as an index of energy available by aerobic means for activity, provided that the animal does not abandon some maintenance function during activity (Moberly, 1968) and provided that oxygen consumption does not increase above activity levels at the termination 
of activity. An increase in oxygen consumption following activity has been noted in two amphibians, Hyla and Batrachoseps (Bennett and Licht, 1973). Since Rana show no such increase during recovery after similar conditions of stimulation (Seymour, 1973) and since Bufo exhibit little fatigue after prolonged activity, measurements of scope are valid indicators of aerobic capacity of these two species.

The aerobic scopes of Bufo and Rana increase continually between 5 and $30^{\circ} \mathrm{C}$ and the scope of the toads is always greater than that of the frogs (Table 1). The maximal aerobic scope of Bufo occurs at $30^{\circ} \mathrm{C}$, a temperature $6^{\circ} \mathrm{C}$ higher than the $T_{\mathrm{b}}$ preferred by fed individuals of that species maintained under field conditions (Carey, 1978). The level of preferred $T_{\mathrm{b}}$ and aerobic scope coincide fairly closely in most reptiles (Bennett and Dawson, 1976). The significance of the disparity in amphibians will be obscure until measurements on more species are completed.

A general pattern of aerobic capacities for activity has emerged indicating that slow, sluggish animals relying on threat postures or a static defense against predators generally have low aerobic scopes and those using rapid escape movements have larger ones (see Bennett, 1978). However, this pattern is reversed in Rana and Bufo. Bennett and Licht (1974) have postulated that predation has selected for the development of high glycolytic, anaerobic capacities in Rana which flee predators rapidly and that Bufo, using poison and inflation to discourage predators, have aerobic capacities since intense selection for anaerobiosis has not occurred. However, large aerobic scope and capacity for prolonged exercise without fatigue in Bufo are correlated with specialized characteristics of respiratory and cardiovascular systems. Bufonid lungs possess a greater percentage of total respiratory capillaries (Czopek, 1955; Bieniak and Watka, 1962) and extensive septa provide greater surface area for gas exchange (Tenney and Tenney, 1970) than those of Rana. Toads have higher blood oxygen capacity due to higher hemoglobin and red blood cell contents (Hillman, 1976; Carey, 1979 b). Toads may also have greater tidal volume during activity and more high-oxidative muscle fibers which have a 6-7 fold higher maintenance cost than typical low-oxidative fibers (Gordon, 1968). If these characteristics require more energy for development and maintenance, they most likely evolved in response to positive selection for aerobic capacities rather than lack of selection for extensive anaerobiosis.

The only time in the annual cycle in which vigourous, prolonged activity has been noted in Bufo b. boreas is during breeding. Male-male aggression involving mounting, pushing, and rapid swimming occurs frequently, even if no females are present. When males and females are in amplexus before egglaying begins, groups of males attempt to pull the male off the female. Such interactions involve rapid movements continuing for 30-45 min over a wide range of $T_{b}$. Clearly, a benefit would be attached to developing extensive aerobic capacities since a male fatiguing in the course of these interactions would be less likely to fertilize the eggs. Rana, on the other hand, show few prolonged aggressive movements during breeding (J. Collins, pers. comm.). These observations need to be tested to see if pronounced aerobic metabolism is invariably correlated with aggressive breeding habits in amphibians. 


\section{Heart Rate during Rest and Activity}

Standard heart rate of Bufo b. boreas is thermally sensitive with a $Q_{10}$ of 2.09 . This value coincides closely with other $Q_{10}$ obtained during rest in amphibians acclimated to laboratory conditions: 2.00 for Bufo fowleri (Stier and Bock, 1966), 2.06 for Rana pipiens (Miller and Mizell, 1972), 2.11 for Rana temporaria (Harri and Talo, 1975), and 1.89 for Rana catesbeiana (Weathers, 1976).

Activity in montane populations of Bufo b. boreas has been recorded at $T_{\mathrm{b}}$ ranging from 0.2 to $33.9^{\circ} \mathrm{C}$ (Carey, 1978). The data presented here for standard and active metabolic and heart rates permit assessment of the contribution of heart rate to active oxygen consumption over such a range of $T_{\mathrm{b}}$. Elevation of heart rate appears to play a minor role in enhancement of oxygen delivery at any $T_{\mathrm{b}}$. The heart rate increment (HRI), the difference between standard and active heart rate, ranges from 10.6 beats $/ \mathrm{min}$ at $5^{\circ} \mathrm{C}$ to 28.7 beats $/ \mathrm{min}$ at $25^{\circ} \mathrm{C}$ (Table 4 ). The HRI is maximal $2^{\circ} \mathrm{C}$ above the mean preferred $T_{\mathrm{b}}$ of these toads in the field (Carey, 1978) and does not coincide with the $T_{\mathrm{b}}$ at which maximal aerobic metabolic scope is observed $\left(30^{\circ} \mathrm{C}\right)$. Heart rate increments of similar sized reptiles at the same $T_{\mathrm{b}}$ are much higher (Gatten, 1974a).

The percentage contribution of heart rate to increased oxygen transport during activity can be calculated according to the equation of Gatten (1974b):

$$
\left[\left(\frac{\mathrm{AHR}-\mathrm{SHR}}{\mathrm{SHR}}\right) \div\left(\frac{\mathrm{AMR}-\mathrm{SMR}}{\mathrm{SMR}}\right)\right] \times 100
$$

The estimated contribution of heart rate to oxygen transport in Bufo decreases from $5 \%$ at $5^{\circ} \mathrm{C}$ to $1.7 \%$ at $30^{\circ} \mathrm{C}$ (Table 4 ). These calculations suggest that stroke volume and/or AV difference must contribute the major amount of oxygen during activity. The contribution of AV difference would be difficult to measure, since oxygenated cutaneous blood drains into the venous flow. However, the variation in contribution of SV and AV difference over a range in $T_{\mathrm{b}}$ can be estimated by calculating the oxygen pulse (oxygen consumption

Table 4. Standard and active oxygen pulse (SOP and AOP), heart rate increment (HRI), oxygen pulse increment (OPinc) and the percentage contribution of heart rate to activity in Bufo b. boreas maintained under field conditions. Values were calculated from Eq. 1, 2, 9 and 10. Percentage contribution of heart rate to oxygen consumption during exercise was estimated from Eq. 11. HRI is in beats/min and SOP, AOP, and OPinc are in $\mathrm{cm}^{3} \mathrm{O}_{2} \times 10^{-5}$ (g. beat)

\begin{tabular}{lcrrrrr}
\hline & $T_{\mathrm{b}}\left({ }^{\circ} \mathrm{C}\right)$ & \multicolumn{1}{c}{} & \\
\cline { 2 - 7 } & 5 & 10 & 15 & 20 & 25 & 30 \\
\hline HRI & 10.6 & 15.5 & 21.0 & 25.9 & 28.7 & 25.9 \\
SOP & 1.14 & 1.14 & 1.27 & 1.34 & 1.44 & 1.50 \\
AOP & 10.55 & 14.00 & 17.18 & 19.79 & 20.30 & 21.99 \\
OPinc & 9.41 & 12.86 & 15.91 & 18.45 & 18.86 & 24.40 \\
\% contribution & 5.16 & 3.82 & 3.34 & 2.78 & 2.49 & 1.71 \\
\hline
\end{tabular}


divided by heart rate at each $T_{\mathrm{b}}$ ). As might be anticipated, oxygen pulse plays an important role in oxygen supply, particularly at high $T_{\mathrm{b}}$ (Table 4). Active values for oxygen pulse (AOP) exceed resting values by 10-20 times. The maximum oxygen pulse for toads, $24.4 \mathrm{~cm}^{3} \mathrm{O}_{2} \times 10^{-5}(\mathrm{~g} \cdot \text { beat })^{-1}$ exceeds all values available for reptiles (Gatten, 1974a). Further studies are necessary to determine if the pattern here is typical of other amphibians.

\section{Anaerobic Metabolism during Activity}

Anaerobic scope is the difference between mass-specific, total body resting lactate concentrations and lactate levels following 5 and $10 \mathrm{~min}$ of vigorous activity in Rana and Bufo, respectively. This measurement allows an estimation of the energy provided for activity by anaerobic glycolysis. The high aerobic scope and low anaerobic scope of Bufo and the opposite relation for Rana (Table 1) at all $T_{\mathrm{b}}$ are consistent with the marked inverse relation between these functions observed previously in amphibians (Bennett and Licht, 1973; Seymour, 1973). As with other functions, anaerobic scope is thermally dependent in both groups.

The contribution of aerobic and anaerobic pathways to the total energy expenditure during activity can be estimated by converting oxygen consumption and lactate generation to ATP production, according to the equations provided by Bennett and Licht (1972): $1.0 \mathrm{mg}$ lactate $=0.0167 \mathrm{mM} \mathrm{ATP}$ and $1.0 \mathrm{~cm}^{3}$ oxygen consumed $=0.290 \mathrm{mM}$ ATP. Aerobic energy production accounts for 60,78 , and $82 \%$ of the total energy expenditure by Bufo during $10 \mathrm{~min}$ of activity at 10,20 , and $30^{\circ} \mathrm{C}$, respectively. In contrast, aerobic metabolism accounts for 17,32 , and $43 \%$ of the total ATP production during $5 \mathrm{~min}$ of activity by Rana at similar temperatures (Fig. 5). Total ATP production, estimated in this manner, is a temperature dependent process in both amphibians over the range of 10 to $30^{\circ} \mathrm{C}$.

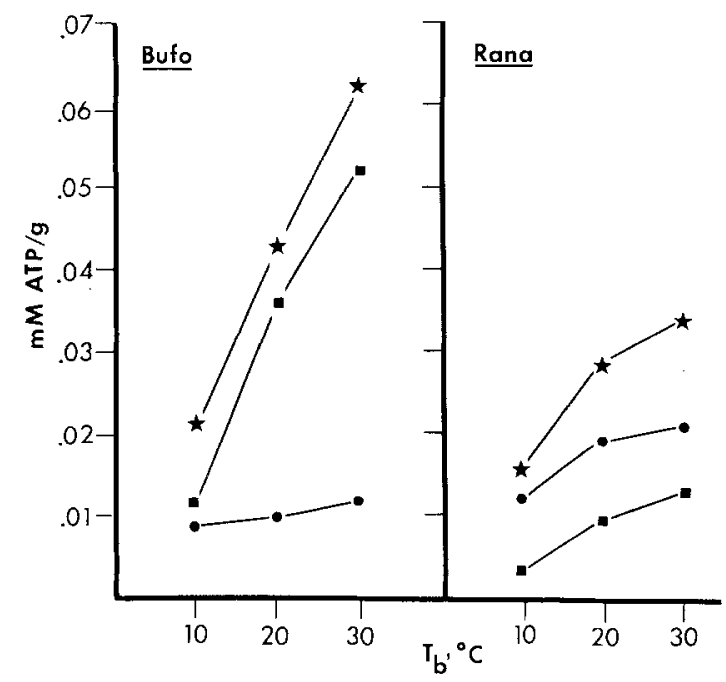

Fig. 5. Estimation of mass-specific production of ATP by Bufo b. boreas and Rana pipiens during $10 \mathrm{~min}$ and $5 \mathrm{~min}$ vigorous activity, respectively. Circles represent ATP production from anaerobic metabolism, calculated from lactate concentration. Aerobic ATP production is represented by squares. Stars signify the sum of ATP production by anaerobic and aerobic means. Estimates are based on the data presented in Figs. 1,2, and 3 
Estimation of ATP production during activity using oxygen consumption and lactate production is a commonly accepted practice (see Bennett, 1978) and is based on the following assumptions: 1) a $\mathrm{P} / \mathrm{O}$ ratio of 3,2) lactate is the only end product of anaerobic ATP production, 3) lactate is not metabolized during activity, and 4) creatine phosphate is not utilized or resynthesized during activity. The first three assumptions are discussed by Cerretelli et al. (1972) and Bennett (1978), but the latter assumption could lead to an underestimation of the total energy expenditure during an activity bout.

Frog muscle contains about $3 \mu \mathrm{M} \mathrm{ATP/g}$ tissue which could suffice for about 10 contractions (Carlson and Wilkie, 1974). Cellular ATP is in equilibrium with creatine phosphate ( $\mathrm{PCr}$ ) according to the relation: $\mathrm{ATP}+\mathrm{Cr} \rightleftharpoons \mathrm{ADP}+\mathrm{PCr}$. Creatine phosphate is present in cells in the approximate concentration of $20 \mu \mathrm{M} /$ g, a sufficient amount to support 80 to 100 twitches of frog muscle (Carlson and Wilkie, 1974). Lactic acid production during contraction of frog muscle does not commence until the concentration of $\mathrm{PCr}$ has dropped to a minimal level (Karpatkin et al., 1964; Cerretelli et al., 1972). Since some initial muscle activity should be supported by $\mathrm{PCr}$, the contribution of $\mathrm{PCr}$ to energy expenditure during activity in amphibians deserves further attention.

Acknowledgements. This study was supported by NSF grant GB-41454 for support of doctoral research in the field sciences, The Theodore Roosevelt Memorial Fund of The American Museum of Natural History, and NSF grant GB-25986 for the study of Systematics and Evolutionary Biology. Dr. William R. Dawson graciously provided laboratory facilities, advice, and encouragement throughout the study. Laboratory facilities at the Rocky Mountain Biological Laboratory were provided by Dr. John C. Johnson, Jr. Critical comments on a former draft of the manuscript were rendered by W.R. Dawson, B.E. Frye, C. Gans, and M.M. Martin.

\section{References}

Aleksiuk, M.: Metabolic and behavioural adjustments to temperature in the red-sided garter snake (Thamnophis sirtalis parietalis): an integrated approach. J. Thermal Biology 1, 153-156 (1976)

Bayne, B.L., Thompson, R.J., Widdows, J.: Some effects of temperature and food on the rate of oxygen consumption by Mytilus edulis L. In: Effects of temperature on ectothermic organisms (W. Wieser, ed.), pp. 181-193. Berlin-Heidelberg-New York: Springer 1973

Bennett, A.F.: The effect of activity on oxygen consumption, oxygen debt, and heart rate in the lizards Varanus gouldii and Sauromalus hispidus. J. comp. Physiol. 79, 259-280 (1972)

Bennett, A.F.: Activity metabolism of the lower vertebrates. Ann. Rev. Physiol. 40, 447-469 (1978)

Bennett, A.F., Dawson, W.R.: Metabolism. In: Biology of the reptilia. Vol. 5, Physiology A. (C. Gans, W.R. Dawson, eds.), pp. 127-223. New York: Academic 1976

Bennett, A.F., Licht, P.: Anaerobic metabolism during activity in lizards. J. comp. Physiol. 81, 277-288 (1972)

Bennett, A.F., Licht, P.: Relative contributions of anaerobic and aerobic energy production during activity in amphibia. J. comp. Physiol. 87, 351-360 (1973)

Bennett, A.F., Licht, P.: Anaerobic metabolism during activity in amphibians. Comp. Biochem. Physiol. 48 A, 319-327 (1974)

Bieniak, A., Watka, R.: Vascularization of respiratory surfaces in Bufo cognatus Say and Bufo compactilis Wiegman. Bull. Acad. Polon. Sci., Ser. Sci. Biol. 10, 9-12 (1962)

Brett, J.R.: Energetic responses of salmon to temperature. A study of some thermal relations in the physiology and freshwater ecology of sockeye salmon (Onchorhynchus nerka). Am. Zool. 11, $99-113(1971)$

Brett, J.R., Glass, N.R.: Metabolic rates and critical swimming speeds of sockeye salmon (Oncorhychus nerka) in relation to size and temperature. J. Fish. Res. Bd. Canada 30, 379-387 (1973) 
Bullock, T.H.: Compensation for temperature in the metabolism and activity of poikilotherms. Biol. Rev. 30, 311-342 (1955)

Carlson, F.D., Wilkie, D.R.: Muscle physiology. 170 pp. Englewood Cliffs: Prentice-Hall 1974

Carey, C.: Factors affecting body temperatures of toads. Oecologia (Berl.) 35, 197-219 (1978)

Carey, C.: Effect of constant and fluctuating temperatures on resting and active oxygen consumption of toads, Bufo boreas. Oecologia 39, 201-212 (1979a)

Carey, C.: Relation of hematology of montane amphibians to fluctuating body temperatures and altitude. (1979b)

Cerretelli, P., Di Prampero, P.E., Ambrosoli, G.: High-energy phosphate resynthesis from anaerobic glycolysis in frog gastrocnemius muscle. Am. J. Physiol. 222, 1021-1026 (1972)

Coyer, P.E., Mangum, C.P.: Effect of temperature on active and resting metabolism in polychaetes. In: Effects of temperature on ectothermic organisms (W. Wieser, ed.), pp. 173-180. BerlinHeidelberg-New York: Springer 1973

Czopek, J.: The vascularization of the respiratory surfaces of some Salentia. Zool. Polon. 6, 101-134 (1955)

Dmi'el, R., Rappeport, D.: Effect of temperature on metabolism during running in the lizard Uromastix aegyptius. Physiol. Zool. 49, 77-84 (1976)

Fry, F.E.J.: Effects of the environment on animal activity. Publ. Ont. Fish. Res. Lab. 68, 1-62 (1947)

Fry, F.E.J.: Temperature compensation. Ann. Rev. Physiol. 20, 207-224 (1958)

Fry, F.E.J., Hochachka, P.W.: Fish. In: Comparative physiology of thermoregulation. Vol. 1 (G.C. Whittow, ed.), pp. 79-134. New York: Academic 1970

Gatten, R.E.: Effects of temperature and activity on aerobic and anaerobic metabolism and heart rate in the turtles Pseudemys scripta and Terrepene ornata. Comp. Biochem. Physiol. 48A, 619-648 (1974a)

Gatten, R.E.: Percentage contribution of increased heart rate to increased oxygen transport during activity in Pseudemys scripta, Terrepene ornata and other reptiles. Comp. Biochem. Physiol. 48 A, 649-652 (1974b)

Gordon, M.S.: Oxygen consumption of red and white muscles from tuna fishes. Science 159, $87-89(1968)$

Harri, M.N.E., Talo, A.: Effect of season and temperature acclimation on the heart rate-temperature relationship in the frog, Rana temporaria. Comp. Biochem. Physiol. 50 A, 469-472 (1975)

Hazel, J.R., Prosser, C.L.: Molecular mechanisms of temperature compensation in poikilotherms. Physiol. Rev. 54, 620-677 (1974)

Hillman, S.S.: Cardiovascular correlates of maximal oxygen consumption rates in anuran amphibians. J. comp. Physiol. 109, 199-207 (1976)

Hochachka, P.W., Somero, G.N.: Strategies of biochemical adaptation. 358 pp. Philadelphia: Saunders 1973

Hutchison, V.H., Whitford, W.G., Kohl, M.: Relation of body size and surface area to gas exchange in anurans. Physiol. Zool. 41, 65-85 (1968)

Karpatkin, S., Helmreich, E., Cori, C.F.: Regulation of glycolysis in muscle. II. Effect of stimulation and epinephrine in isolated frog sartorius muscle. J. Biol. Chem. 239, 3139-3145 (1964)

Mangum, C.P., Sassaman, C.: Temperature sensitivity of active and resting metabolism in a polychaetous annelid. Comp. Biochem. Physiol. 30, 111-116 (1969)

Miller, L.C., Mizell, S.: Seasonal variation in heart rate response to core temperature changes. Comp. Biochem. Physiol. 42 A, 773-779 (1972)

Moberly, W.R.: The metabolic responses of the common iguana, Iguana iguana, to activity under restraint. Comp. Biochem. Physiol. 27, 1-20 (1968)

Newell, R.C.: Effect of temperature on the metabolism of poikilotherms. Nature, Lond. 212, 426-428 (1966)

Newell, R.C., Bayne, B.L.: A review of temperature and metabolic acclimation in intertidal marine invertebrates. Neth. J. Sea Res. 7, 421-433 (1973)

Newell, R.C., Northcroft, H.R. : A re-interpretation of the effect of temperature on the metabolism of certain marine invertebrates. J. Zool., Lond. 151, 277-298 (1967)

Newell, R.C., Pye, V.I.: Seasonal changes in the effect of temperature on the oxygen consumption of the winkle Littorina littorea (L.) and the mussel Mytilus edulis L. Comp. Biochem. Physiol. 34, 367-383 (1970) 
Newell, R.C., Pye, V.I. : Quantitative aspects of the relationship between metabolism and temperature in the winkle Littorina littorea (L.). Comp. Biochem. Physiol. 38 B, 635-650 (1971)

Precht, H.: Constant systems. In: Temperature and life (H. Precht, J. Christophersen, H. Hensel, W. Larcher, eds.), pp. 302-310. Berlin-Heidelberg-New York: Springer 1973

Prosser, C.L.: General summary: the nature of physiological adaptation. In: Physiological adaptation (C.L. Prosser, ed.), pp. 167-180. Washington, D.C.: American Physiological Society (1958)

Seymour, R.S.: Physiological correlates of forced activity and burrowing in the spadefoot toad, Scaphiopus hammondii. Copeia 1973, 103-115 (1973)

Stier, T.J.B., Bock, H.C.: Seasonal changes of heart rate-temperature relationship in toads. Proc. Soc. exp. Biol. Med. 123, 149-151 (1966)

Tashian, R.E., Ray, C.: The relation of oxygen consumption to temperature in some tropical, temperate and boreal anuran amphibians. Zoologica 42, 63-68 (1957)

Tenney, S.M., Tenney, J.B.: Quantitative morphology of cold-blooded lungs: Amphibia and Reptilia. Resp. Physiol. 9, 197-215 (1970)

Tribe, M.A., Bowler, K.: Temperature dependence of "standard metabolic rate" in a poikilotherm. Comp. Biochem. Physiol. 25, 427-436 (1968)

Turney, L.D., Hutchison, V.H.: Metabolic scope, oxygen debt and the diurnal oxygen consumption cycle of the leopard frog, Rana pipiens. Comp. Biochem. Physiol. 49 A, 583-601 (1974)

Weathers, W.W.: Influence of temperature acclimation on oxygen consumption, haemodynamics and oxygen transport in bullfrogs. Aust. J. Zool. 24, 321-330 (1976)

Received December 11, 1978 